\title{
A fonoaudiologia entre a objetividade e subjetividade: atuação em uma Enfermaria de Saúde Mental
}

DOI: https://doi.org/10.5935/1984-9044.20200023

\author{
Marilisa Barbosa Hesse ${ }^{12}$ - Universidade Estadual de Campinas (UNICAMP)
}

Resumo: As primeiras práticas fonoaudiológicas descritas na literatura aconteceram na década de 1920, sendo posterior à idealização da profissão de fonoaudiólogo, oriunda da preocupação da medicina e da educação. Este artigo tem por objetivo explicitar os desafios e as contradições encontradas na atuação do núcleo da Fonoaudiologia no campo da Saúde Mental e cuja metodologia parte do levantamento bibliográfico e do relato de experiência em uma Enfermaria de Saúde Mental em Hospital Geral (HG). Assim, o texto elucida a construção do núcleo da fonoaudiologia e propõe, a partir do campo da saúde mental, o desvio do olhar de um paradigma que estruturou e ainda estrutura a categoria profissional fonoaudiológica. Para que o fonoaudiólogo possa atuar em uma nova perspectiva, é preciso superar os reducionismos e entender que as necessidades não se reduzem àquelas apreensíveis por uma única disciplina clínica.

PALAVRAS-CHAVE: saúde mental; hospital geral; fonoaudiologia.

\section{Phonoaudiology between objectivity and subjectivity: performance in a mental health nursing}

\begin{abstract}
The first speech therapy practices described in the literature took place in the 1920s, after the idealization of the speech therapist profession, arising from the concern of medicine and education. This article aims to explain the challenges and contradictions found in the performance of the core of Speech Therapy in the field of Mental Health whose methodology starts from the bibliographic survey and the report of experience in a Mental Health Ward in General Hospital (GH). Thus, the text elucidates the construction of the core of speech therapy and proposes, from the field of mental health, the deviation from the look of a paradigm that structured and still structures the speech therapy professional category. For the speech therapist to be able to act in a new perspective, it is necessary
\end{abstract}

\footnotetext{
${ }^{1}$ Artigo baseado no Trabalho de Conclusão de Curso da autora, sob orientação de Bruno Ferrari Emerich

2 ORCID: https://orcid.org/0000-0002-7188-0442
} 
to overcome reductionisms and understand that the needs are not reduced to those apprehended by a single clinical discipline.

KEY WORDS: mental health; general hospital; speech therapy

\section{Palifemiando a história da fonoaudiologia}

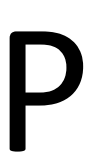

alifemia é definida como uma

manifestação primária no

balbucio de uma criança com repetições de uma palavra ou

sílaba. O termo aqui inserido traz a ideia do início desse estudo, porém, também traz a ideia de repetição, como a história da Fonoaudiologia.

Referenciaremos aqui as origens desse campo profissional ao longo dos anos de prática clínica a fim de propiciar subsídios para a discussão posterior. Para isso, este tópico traz diversos recortes bibliográficos de autoras e autores que trataram do tema como tentativa de resgatar a história da Fonoaudiologia no Brasil, especialmente no estado de São Paulo.
Para Figueredo Neto (1988), o caminho no reconhecimento de identidades é algo fundamental na superação do tecnicismo e imediatismo que caracterizam o discurso fonoaudiológico, tal como ele se apresenta hoje. Os primeiros relatos de práticas fonoaudiológicas descritos aconteceram na década de 1920, dentro da instituição escolar, em São Paulo, como um dos instrumentos de homogeneização da fala no Brasil e como uma tentativa de apagamento das diversidades culturais e sociais existentes na língua, objetivando alcançar um controle sistemático da língua brasileira, como forma de controlar as influências de estrangeiros. Analisando o contexto sócio histórico do país, o Brasil se via inserido em um ideário mundial de 
A FONOAUDIOLOGIA ENTRE A OBJETIVIDADE E SUBJETIVIDADE: ATUAÇÃO EM UMA ENFERMARIA DE SAÚDE MENTAL

"Eugenia Social" que se construía no pré II Guerra Mundial, a partir da década de 1920, mostrando uma política sistemática de controle da língua que criava a necessidade de medidas para sua padronização e normatização. Portanto, pretendia-se combater as chamadas "impurezas da língua" para adoção de uma língua nacional padrão, além da intenção, de cunho social, da uniformização da língua, buscando unidade nacional, disciplina e ordem. Nesse período, surge a primeira alusão a uma necessidade de um profissional para atuar na "eliminação" desses desvios de fala, destacando para essa tarefa um professor especializado (Figueredo Neto, 1988).

A partir disso, a medicalização dos problemas sociais fez surgir a patologização da fala, que passou a contar com médicos para o diagnóstico e professores, na época os chamados ortofonistas, para sua correção (Figueredo Neto, 1988). O fazer do profissional era caracterizado basicamente por exercícios de correção da pronúncia e de inibição do uso de estrangeirismos. Embora toda a atividade fosse baseada no diálogo, a ele não era atribuído o estatuto de método de trabalho. Para legitimar a avaliação fonoaudiológica ou mesmo a terapêutica a ser empreendida, bastava buscar na Medicina as características previamente determinadas para cada patologia (Oliveira, 2002). A leitura da patologia, sob a ótica da chamada Clínica da Objetividade defendida na época, subtraía a singularidade e impunha um tratamento ortopédico às realidades humanas (Palladino, 2000).

Somente na década de 1960, mais precisamente em 1961, deu-se início ao ensino formal da Fonoaudiologia no Brasil, com a criação de dois cursos de formação voltados à graduação de tecnólogos em Fonoaudiologia. A então institucionalização da Fonoaudiologia surge como uma forma de legitimar a padronização da fala que há décadas já vinha sendo desenvolvida, vinculada ao 
A FONOAUDIOLOGIA ENTRE A OBJETIVIDADE E SUBJETIVIDADE: ATUAÇÃO EM UMA ENFERMARIA DE SAÚDE MENTAL

universo médico $^{3}$ e educacional (Figueredo Neto, 1988). Para Oliveira (2002), o referencial médico entra como alicerce do diagnóstico e o referencial educacional como aquele que sustenta a terapêutica fonoaudiológica.

Nos anos 1970, tiveram início os movimentos pelo reconhecimento dos cursos de Fonoaudiologia. Foram criados, então, os cursos em nível de bacharelado, sendo o curso da Universidade de São Paulo (USP) na cidade de São Paulo o primeiro no Brasil a ter seu funcionamento autorizado, em 1977. Na década seguinte, foi regulamentada a profissão de fonoaudiólogo em território nacional e

\section{Objetivos}

O objetivo deste trabalho é explicitar os desafios e as contradições encontradas

\footnotetext{
${ }^{3}$ Um exemplar dessa situação na atualidade é a incorporação da Classificação Internacional de Doenças (CID) e do Manual Diagnóstico e Estatístico de Transtornos Mentais (DSM) pela
}

disposto sobre sua atividade profissional (Brasil, 1981).

Moreira e Mota (2009) apontam que, entre as décadas de 1970 e 1980, os fonoaudiólogos iniciaram o trabalho na saúde pública via secretarias de educação e saúde. Na segunda metade dos anos 1980, com a criação do SUS, surgiram os concursos públicos para as Secretarias de Saúde, com a contratação de fonoaudiólogos, porém, apenas em 2002, com a regulamentação do modelo de atenção à Saúde Mental Infanto Juvenil, o fonoaudiólogo é, segundo Almeida (2014), referido como integrante das equipes dos Centros de Atenção Psicossocial Infanto Juvenil (CAPS IJ).

na atuação do núcleo especializado da Fonoaudiologia no campo da Saúde Fonoaudiologia como resposta à necessidade de designar e nomear patologias. 
A FONOAUDIOLOGIA ENTRE A OBJETIVIDADE E SUBJETIVIDADE: ATUAÇÃO EM UMA ENFERMARIA DE SAÚDE MENTAL

Mental a partir de uma experiência em uma Enfermaria de Saúde Mental em Hospital Geral (HG).

Procurou-se relacionar os fatos históricos que colaboram no esclarecimento da

\section{Metodologia}

Este estudo foi realizado em uma Enfermaria de Saúde Mental em HG durante o segundo ano enquanto fonoaudióloga residente pelo Programa Multiprofissional em Saúde Mental da Universidade Estadual de Campinas (UNICAMP). A discussão foi desenvolvida a partir de levantamentos bibliográficos em base de dados virtuais em saúde além da consulta a documentos e manuais impressos baseados nos seguintes temas: saúde mental, hospital geral e fonoaudiologia. A construção deste trabalho também foi apoiada no relato de experiência, compreendida como "aquela que nos passa, nos acontece, nos

\footnotetext{
"O termo "usuário" será aqui utilizado tendo em vista que seu caráter é capaz de
}

identidade do profissional fonoaudiólogo a fim de contribuir para o aprofundamento da discussão sobre as possibilidades da atividade fonoaudiológica junto ao campo da Saúde Mental.

toca", segundo a definição de Bondía (2002).

Usamos da estrutura narrativa como ferramenta metodológica, sendo essa uma categoria de mediação entre a experiência e o discurso (Onocko Campos e Furtado, 2008) e, em razão disso, o texto é organizado a partir de casos e vinhetas clínicas para endossar a discussão teórica apresentada ao longo do texto. Os casos são expostos com nomes fictícios com 0 intuito de preservar as identidades dos usuários ${ }^{4}$ que serviram a este estudo como exemplos de intervenções clínicas.

ultrapassar o ideário passivo ou liberal dos termos "paciente" ou "cliente". 


\section{A bradicinesia fonoaudiológica ao adentrar o universo da saúde coletiva}

Bradicinesia faz referência a um movimento lento de determinada ação. O termo é introduzido neste tópico para fazer alusão à velocidade do processo de entrada da Fonoaudiologia na Saúde Coletiva.

A inserção da Fonoaudiologia nas políticas públicas do país teve seu início entre 1970 e 1980, inicialmente na área educacional e, posteriormente, expandindo-se para saúde e assistência social (Moreira e Mota, 2009). Nessa época, o número de profissionais era pequeno, os trabalhos isolados, sem nenhum tipo de integração ou propostas abrangentes (Moreira e Mota, 2009) e os procedimentos fonoaudiológicos eram voltados para estrutura de consultas ambulatoriais, devido à formação reabilitadora dos fonoaudiólogos.

Com a criação do SUS e o surgimento dos concursos públicos para as Secretarias de
Saúde, passam a ser contratados fonoaudiólogos, principalmente no estado de São Paulo (Moreira e Mota, 2009), tendo destaque, de acordo com Befi (1997), a inserção da Fonoaudiologia na Atenção Primária à Saúde (APS). Porém, a atuação fonoaudiológica permaneceu com a estrutura de atendimentos semelhante aos do consultório, mantendo a atuação individualista e reabilitadora, comprometendo a efetividade do trabalho da profissão e não surtindo efeito na comunidade em geral e nos órgãos competentes (Befi, 1997; Moreira e Mota, 2009). Além disso, destaca-se que a inserção da Fonoaudiologia na Saúde Pública tem suas raízes calcadas no cuidado voltado à saúde e proteção na infância e adolescência, seguindo a trajetória de sua formação.

Com a expansão dos serviços públicos de assistência à saúde e a ampliação dos 
A FONOAUDIOLOGIA ENTRE A OBJETIVIDADE E SUBJETIVIDADE: ATUAÇÃO EM UMA ENFERMARIA DE SAÚDE MENTAL

direitos dos usuários, houve a necessidade de reorientação da prática fonoaudiológica, ampliando suas ações para além de ações de reabilitação, ademais da inserção do profissional no campo da Saúde Mental (Miranda et al, 2015).

\section{O percurso coclear da reforma psiquiátrica brasileira em ressonância com a fonoaudiologia}

A cóclea é conhecida por sua anatomia circular, sendo uma cavidade cônica do ouvido interno. $O$ termo é aqui utilizado fazendo alusão à forma com que será a apresentação desse tópico, em espiral, ligando fatos de uma extremidade à outra com repercussão entre os pontos.

A Reforma Psiquiátrica Brasileira é um processo social complexo que repensa o cuidado em Saúde Mental, à medida que supera as reformulações na organização dos serviços de saúde, nega a instituição manicomial, rompe com a racionalidade e o saber psiquiátrico sobre a doença mental e questiona o poder do especialista (Yasui, 2010; Desviat, 2015).
A Fonoaudiologia entra mais efetivamente no campo da Saúde Mental a partir de 1992, com base na diretriz da multiprofissionalidade na prestação de serviços às pessoas em sofrimento psíquico (Brasil, 1992). Esse período, para Almeida (2014), é o início de uma inflexão no trabalho com os sujeitos institucionalizados por transtornos mentais, por meio da qual se delineia um novo cenário na Saúde Mental brasileira, ganhando impulso $o$ trabalho das equipes interdisciplinares e, com elas, o desafio de, em conjunto, reconstruir a história da Saúde Mental no Brasil.

A justificativa para a composição de equipes interdisciplinares no trabalho 
A FONOAUDIOLOGIA ENTRE A OBJETIVIDADE E SUBJETIVIDADE: ATUAÇÃO EM UMA ENFERMARIA DE SAÚDE MENTAL

com os sujeitos com transtornos mentais deriva, principalmente, da multiplicidade e diversidade das demandas dos usuários e da consequente necessidade de trocas e integração de saberes (Brasil, 1992). Portanto, de acordo com Amarante (2008), o trabalho com Saúde Mental é uma tarefa que compete a diversos profissionais de saúde, o que nos impulsiona a argumentar em favor da inserção do fonoaudiólogo nas equipes dos serviços de Saúde Mental.

A atuação do fonoaudiólogo é influenciada pela história da inserção e atuação fonoaudiológica na Saúde Pública (Almeida, 2014). Como reação a uma conceituação do patológico, que não levava em consideração a posição subjetiva do doente perante a doença, a Fonoaudiologia passou a buscar na Linguística os conceitos que the permitiriam dar conta dos fenômenos patológicos da linguagem (Cunha, 2001). Ao mesmo tempo, passou-se a questionar se reduzir os sintomas da linguagem a alterações do sistema da língua compreenderia a singularidade do sintoma e abarcaria a subjetividade do sujeito. Percebe-se que a prática clínica fonoaudiológica é influenciada por diversos campos de conhecimento, o que foi chamado por Cunha (2001) como "clínica de empréstimos".

A partir do início de 2011, há intensificação da implantação da Rede de Atenção à Saúde (RAS), como aposta para maior integralidade do cuidado, qualificação e fortalecimento dos princípios do SUS. Uma dessas redes é a Rede de Atenção Psicossocial (RAPS), que traz como pontos de atenção os Leitos de Saúde Mental em Hospital Geral (LSMHG) (Brasil, 2017).

Os LSMHG existem mesmo antes da implementação da RAPS. Apesar de ter havido um aumento gradativo das Enfermarias de Saúde Mental em HG (Dalgalarrondo et al, 2003), observamos alguns desafios no que se refere à expansão e modo de organização desses pontos de atenção. É necessário superar as concepções de Reforma Psiquiátrica que restringem seu processo a uma simples reorganização dos serviços ou como um modelo fechado, tratando-se de um processo em constante movimento e transformação (Amarante, 2008; Desviat, 2015). 
A FONOAUDIOLOGIA ENTRE A OBJETIVIDADE E SUBJETIVIDADE: ATUAÇÃO EM UMA ENFERMARIA DE SAÚDE MENTAL

Segundo Dias (2010), os LSMHG são disponibilizados aos usuários em situação de crise que necessitem de retaguarda de cuidado intensivo, como uma estratégia dentro do Projeto
Terapêutico Singular (PTS) construído com sua equipe de referência, dependendo do tipo da complexidade de cuidado demandada pelo usuário.

\section{Acesso lexical na descrição de uma enfermaria de saúde mental}

O termo acesso lexical é usado na Fonoaudiologia como uma habilidade de liberação de informações a partir de um campo semântico ou fonológico. $O$ termo é aqui inserido como forma de seguir este trabalho descrevendo livremente a Enfermaria de Saúde Mental do Hospital de Clínicas (HC) da UNICAMP que serviu de campo de atuação e reflexão e possibilitou a produção deste trabalho.

No ano de 1986 foi implantada a Unidade de Internação Psiquiátrica no $\mathrm{HC}$ da UNICAMP, assim chamada inicialmente, com 14 leitos. A unidade iniciou suas atividades durante a desinstitucionalização de um grande número de pacientes que moravam em hospitais psiquiátricos (Dalgalarrondo et al, 2003).

A equipe contém composição biomédica, constituindo-se de médicos residentes em Psiquiatria do Departamento de Psicologia Médica e Psiquiatria; médicos psiquiatras que ministram as chamadas "visitas clínicas"; enfermeiros; técnicos de enfermagem alternados e distribuídos entre os turnos da manhã, tarde e noite; e profissionais de outros núcleos de atuação abarcando residentes multiprofissionais em Saúde Mental do Departamento de Saúde Coletiva e psicólogos em treinamento pelo Departamento de Psicologia Médica e Psiquiatria. 
A FONOAUDIOLOGIA ENTRE A OBJETIVIDADE E SUBJETIVIDADE: ATUAÇÃO EM UMA ENFERMARIA DE SAÚDE MENTAL

A equipe é composta por profissionais que atuam separadamente a partir dos núcleos de formação, tornando o funcionamento do serviço fragmentado e solitário nesse sentido. A construção da Enfermaria se baseou predominantemente no ensino em serviço aos médicos residentes em Psiquiatria, justificando o caráter biomédico presente nas discussões e nos arranjos do trabalho cotidiano.

\section{A contrariedade da habilidade de figura fundo no universo fonoaudiológico}

Figura fundo é uma das habilidades do Processamento Auditivo Central (PAC), sendo definida como a capacidade em selecionar um estímulo sonoro significativo dentro de uma gama de sons apresentados no ambiente. Metaforicamente ao termo, torna-se um desafio na clínica fonoaudiológica identificar sinalizadores sem desconsiderar o que está oculto, ao fundo.

A categoria profissional aqui estudada, a Fonoaudiologia, ainda busca formas de integrar saberes, tanto conjuntamente a outros núcleos de saberes, quanto às especialidades presentes dentro da própria classe. $\mathrm{O}$ argumento de que os sujeitos envolvidos na saúde têm uma história de vida, com sonhos e aspirações, indica que a integralidade só se realiza quando procuramos estabelecer uma relação sujeito-sujeito, implicando uma abertura para o diálogo com o outro (Mattos, 2001). Como afirma Furtado (2007), o desafio de uma formação generalista está na urgência em integrar as diversas disciplinas, saberes e práticas, tendo como foco o cuidado centrado no indivíduo, na família e na coletividade. Para superar os reducionismos, é preciso entender que as necessidades não se reduzem àquelas 
A FONOAUDIOLOGIA ENTRE A OBJETIVIDADE E SUBJETIVIDADE: ATUAÇÃO EM UMA ENFERMARIA DE SAÚDE MENTAL

apreensíveis por uma única disciplina clínica, mas sim se ampliam por várias (Mattos, 2001).
A fim de exemplificar de onde suscita a discussão que faremos posteriormente, descrevemos, a seguir, dois casos clínicos.

\section{Margarida}

Margarida é uma senhora de 47 anos cujos cabelos são lisos e curtos em um tom castanho claro. A paciente ${ }^{5}$ chega à Unidade de Emergência Referenciada (UER) do HC da UNICAMP e é levada em sequência à Unidade de Terapia Intensiva (UTI), onde foi entubada devido a episódio de rebaixamento de consciência relacionado a intoxicação por Lítio. Posteriormente, após extubação, Margarida chega à Enfermaria de Saúde Mental com quadro de confusão mental, taquipsiquismo, taquilalia, agressividade e pensamento desorganizado, associado ainda à perda da consciência. Recebeu

${ }^{5} \mathrm{O}$ termo paciente será utilizado nos relatos apresentados por ser o termo universalmente utilizado em âmbito hospitalar. Além disso, é importante destacar que sua utilização pode sugerir implicitamente uma posição passiva e diagnóstico de Transtorno Afetivo Bipolar (TAB) há 25 anos pela instituição que realiza seu acompanhamento desde então, no município em que reside. Segundo os profissionais desse serviço, Margarida apresentou sua primeira crise de mania aos 22 anos de idade e, ao longo dos anos, manifestou diversos episódios maniatiformes, incluindo sintomas psicóticos intercalados com episódios depressivos.

Aproximo-me de Margarida durante uma atividade no espaço do ateliê em que me pediu para ajudá-la com uma pintura, uma flor margarida. Após tal

hierarquicamente inferior em relação ao profissional, visto que a origem do termo se refere à palavra sofredor, derivada do latim: patiens, de patior, que significa sofrer. 
A FONOAUDIOLOGIA ENTRE A OBJETIVIDADE E SUBJETIVIDADE: ATUAÇÃO EM UMA ENFERMARIA DE SAÚDE MENTAL

aproximação, recebo o título de "terapeuta ocupacional", ainda que tivesse me apresentado como fonoaudióloga desde o início. Margarida me solicita assistência às suas questões vocais já que, segundo ela, gostaria de aprender a cantar e, além disso, diz ter "dificuldades para comer". Resgatando os dados do prontuário, encontro que ela teve paralisia facial na infância e Acidente Vascular Cerebral (AVC) quando jovem adulta. Ao conversar com Margarida, inicialmente percebo assimetria facial com falta de movimentação dos músculos do lado esquerdo do rosto, fala lentificada, salivação excessiva e lacrimejamento dos olhos. Diante de seu pedido de atendimento, me coloco disponível para realizar avaliação e atendimentos fonoaudiológicos.

Descrevo a seguir brevemente as manifestações observadas durante avaliação fonoaudiológica. Alerto o leitor que usarei termos técnicos específicos do universo fonoaudiológico e, para que o texto não sofra interrupções, não farei explicações sobre eles. A avaliação fonoaudiológica foi realizada através da avaliação estrutural da musculatura orofacial, da respiração, fonação, ressonância, articulação, prosódia, sensibilidade intra e extra oral e das funções de mastigação e deglutição. À avaliação estrutural em repouso da musculatura facial, foi observada assimetria de face; da musculatura da língua, observou-se assimetria de língua quanto ao tamanho, sendo maior do lado esquerdo e com fasciculações nas laterais; da musculatura do véu palatino, não foram observadas alterações. À avaliação da respiração, apresentou respiração nasal do tipo torácica com velocidade de respiração acelerada. Os tempos máximos de fonação foram abaixo do valor de normalidade, sugerindo coaptação glótica ineficiente e incoordenação

pneumofonoarticulatória. À avaliação da fonação, percebe-se uma qualidade vocal rouca e tensa, ressonância hiponasal e ataque vocal isocrônico. A intensidade e frequência vocal mostraram-se adequadas. Em relação à ressonância, apresentou movimento velar com mínima movimentação do véu e hiponasalidade. Com relação à 
articulação, apresentou movimentos labiais com mínima força, deterioração progressiva e redução da velocidade durante o movimento. Com relação aos movimentos de língua, foi capaz de realizá-los, porém, de forma inconsistente e com redução da velocidade durante o movimento. $\mathrm{Na}$ tarefa de resistência lingual, observou-se tônus muscular diminuído. Os movimentos mandibulares foram lentos, porém com fechamento completo e sem desvio mandibular. Com relação aos movimentos das bochechas, conseguiu inflar, porém não realizou os movimentos de suflar e lateralizar o ar. Em relação à prosódia, observou-se velocidade de fala anormal e pausas inadequadas para respiração. À estimulação de sensibilidade respondeu adequadamente. Com relação à mastigação, apresentou preferência à direita e presença de resíduos de alimento no dorso da língua e no vestíbulo bucal. Apresentou, à avaliação da função de deglutição, presença de movimentação da cabeça, tensão dos músculos faciais bem como escape de alimento.
Durante a avaliação descrita, Margarida também insere elementos discursivos de sua história de vida. Em determinado momento, diz não ser capaz de realizar o movimento solicitado com os lábios por ter sofrido paralisia facial na infância, infância essa carregada por lembranças de violência física por parentes de seu núcleo familiar. Diz que seu "sofrimento é profundo" e chora ao dizer que sofreu muitas agressões físicas por alguns familiares que moravam em sua casa. 0 processo terapêutico se deu juntamente com o processo avaliativo e, muitas vezes, enquanto pintávamos novas flores margaridas, no espaço do ateliê ou durante o momento do almoço dos pacientes, em que pude acompanhá-la durante sua alimentação; ou ainda enquanto selecionávamos músicas para cantarmos juntas.

Na categoria clínica fonoaudiológica, é comum o encaminhamento para outro profissional também fonoaudiólogo de outra área de especialidade, por exemplo, demandas específicas de deglutição serem avaliadas e acompanhadas por outro profissional fonoaudiólogo da especialidade de 
Disfagia. Por ser a única fonoaudióloga na Enfermaria de Saúde Mental do HC, fui provocada a olhar para as diversas questões fonoaudiológicas de Margarida sem desconsiderar o sofrimento psíquico que trazia, motivo pelo qual estava internada. Dessa forma, pude agrupar as questões fonoaudiológicas em atendimentos únicos que compreendiam questões de fala, voz e deglutição, sendo que cada uma dessas áreas se relaciona a diferentes especialidades clínicas reconhecidas pelo Conselho Federal de Fonoaudiologia (CFFa) atualmente.

Margarida, ao se despedir de mim quando recebeu alta, disse que continuaria com os exercícios fonoaudiológicos não só por fazerem bem a ela, mas por lembrá-la do cuidado para com ela durante a internação. Disse ainda que gostaria que pudéssemos nos encontrar novamente, mas não nos corredores do hospital, e sim nos corredores da vida.

A complexidade da assistência se deu à medida que foi preciso identificar e, posteriormente, integrar os conteúdos subjetivos manifestados a partir da avaliação fonoaudiológica. Margarida deixou como aprendizado que não se pode desconsiderar o saber técnico que a disciplina de Fonoaudiologia carrega, porém, é preciso de fato olhar para além da figura e enxergar nitidamente o fundo, relembrando ao leitor a referência à habilidade de figura fundo citada no início deste tópico

\section{Rosa}

Rosa é uma senhora de 73 anos cujos olhos são um tom especial de azul e seus cabelos são brancos, cortados em uma altura um pouco acima dos ombros. Foi internada na Enfermaria por um encaminhamento do médico que a acompanhava em seu consultório. Segundo familiares, há quatro anos Rosa 
A FONOAUDIOLOGIA ENTRE A OBJETIVIDADE E SUBJETIVIDADE: ATUAÇÃO EM UMA ENFERMARIA DE SAÚDE MENTAL

passou a apresentar alteração progressiva e lenta do paladar, recebendo na época o diagnóstico de Síndrome da Boca Ardente ${ }^{6}$ e Síndrome Depressiva Ansiosa. Rosa dizia estar com "limo na boca" e "coisa estranha na boca". Fazia movimentos repetidos de deglutição com a intenção de engolir o corpo estranho que estava em sua boca, na região do osso maxilar. Segundo familiares, a higienização bucal se tornou um desafio, embora com frequência realizasse procedimento de limpeza bucal. Rosa também dizia sentir sensação de "inundação na boca" ao tomar líquidos e dizia que grãos de arroz pareciam "pedrinhas" em sua boca. Além disso, dizia: "minha boca não é minha" com perda de familiaridade com a própria boca. Com a intensificação de tais sensações, Rosa inicialmente reduziu a ingestão de alimentos pela boca e progrediu para ingestão apenas de alimentos pastosos e líquidos, também em quantidades reduzidas. Perdeu cerca

\footnotetext{
${ }^{6}$ A Síndrome da Boca Ardente é caracterizada por dor na cavidade oral com ou sem sinais inflamatórios, mas sem lesões específicas na mucosa oral. Geralmente apresenta-se como
}

de 15 quilos em 4 meses e, após tal acontecimento, entendeu-se a necessidade de realizar passagem de Sonda Nasoenteral (SNE) para realimentação, seguindo em repouso em ambiente domiciliar. Foi internada após apresentar agravo das sensações relacionadas à boca, restringir-se voluntariamente à cama, passar a movimentar-se menos por ter "perdido as forças", manter os olhos fechados e passar a falar somente o que the era perguntado, não iniciando novos diálogos.

Em seu quarto, Rosa é encontrada sozinha, sentada em uma poltrona, segurando um copo de água. Digo que gostaria de conhecê-la dizendo meu nome e minha profissão e logo em seguida Rosa se apresenta e pergunta se eu posso ajudá-la com sua boca. $O$ curto pedido ficou longo na boca de Rosa que disse com velocidade de fala lentificada e em tom monótono. Respondo que sim, poderia ajudá-la, e que poderíamos fazer

dor na boca, alterações do paladar e alterações da salivação. 
A FONOAUDIOLOGIA ENTRE A OBJETIVIDADE E SUBJETIVIDADE: ATUAÇÃO EM UMA ENFERMARIA DE SAÚDE MENTAL

uma avaliação das estruturas da boca e de suas funções para vermos como elas estavam funcionando. Durante esse processo, um dos movimentos solicitados era a retração e protrusão dos lábios com a emissão do "i" seguida com a emissão do "u". Após concluir o movimento, Rosa comenta: "esse é difícil, pois parece um sorriso e eu nem me lembro a última vez que sorri". Embora tenha conseguido realizar o exercício, digo que esse me pareceu ter sido difícil mesmo e que poderíamos tentar mais vezes em outros momentos. Após alguns movimentos, pergunto como ela estava. Rosa me responde que a boca estava "cansada" e proponho que continuássemos nos próximos dias. Percebi maior abertura para realização dos movimentos quando eu informava que aquele movimento poderia ser difícil, mas que a ideia era tentar executar os movimentos e não necessariamente conseguir. Rosa não se recusou a tentar realizar nenhum dos movimentos solicitados e, na maioria das vezes, foi capaz de realizá-los mesmo com algumas dificuldades.
Assim como a descrição da avaliação do caso anterior, não me deterei em explicar os termos fonoaudiológicos em prol da continuidade do texto. À avaliação estrutural em repouso da musculatura facial, aparência e condições posturais, foram encontrados lábios selados com tensão, condição postural da mandíbula normal, aspecto flácido das bochechas, assimetria facial com lado direito aumentado, posição da língua contida na cavidade oral e aspecto normal do palato duro. Com relação à mobilidade, apresentou movimentos labiais de protrusão, retração, lateralidade direita esquerda com mínima força e redução da velocidade durante o movimento. Com relação aos movimentos de língua, foi capaz de protruir, retrair, lateralizar para direita e para esquerda, elevar e abaixar, porém, de forma inconsistente. À tarefa de resistência lingual, observou-se tônus muscular diminuído. Os movimentos mandibulares de abaixar e elevar foram lentos, porém com fechamento completo e sem desvio mandibular. Os movimentos de lateralização para direita e para esquerda e protrusão não foram realizados. Com relação aos movimentos 
das bochechas, conseguiu inflar, porém, não realizou os movimentos de suflar e lateralizar o ar. Em relação à prosódia, observou-se inflexão monótona, como já descrito, a intensidade vocal flutuava em alguns momentos, porém, com predomínio de monoaltura e monointensidade, velocidade de fala lenta e pausas inadequadas para respiração. À avaliação da função respiração, Rosa apresentou respiração nasal do tipo torácica com velocidade de respiração diminuída. Os tempos máximos de fonação foram abaixo do valor de normalidade, sugerindo coaptação glótica ineficiente e incoordenação

pneumofonoarticulatória. Na avaliação da fonação, percebe-se uma qualidade vocal soprosa e monótona e ataque vocal isocrônico. A intensidade vocal se mostrou baixa e a frequência vocal mostrou-se adequada. À estimulação de sensibilidade nas regiões dos lábios, cavidade bucal e língua, respondeu adequadamente ao lado direito e com menos intensidade do lado esquerdo. Com relação à função mastigação, apresentou preferência à direita e presença de resíduos de alimento no dorso da língua e no vestíbulo bucal. Apresentou deglutição atípica com projeção de língua anterior e participação da musculatura perioral com ausência de movimentação de cabeça bem como de escape de alimento. Quanto à eficiência da deglutição com sólidos e líquidos, Rosa não realizou a repetição da deglutição do mesmo bolo.

Durante os atendimentos de Rosa, buscou-se significar a representação do sintoma trazido à boca fazendo uso das técnicas fonoaudiológicas sem retirar de cena o contexto de vida em que se inseria. Mello (2012) utilizou a noção psicanalítica de sintoma como uma contribuição para $\circ$ tratamento fonoaudiológico dos sintomas da fala com o objetivo de ultrapassar a mera descrição do sintoma em prol da sua interpretação, contribuindo para que se evite reduzir os sintomas da fala a patologias fisiológicas ou a desvios das normas da língua. Ainda segundo a autora, considera-se essencial que o tratamento dos sintomas de fala abarque a singularidade dos casos e a diversidade 
A FONOAUDIOLOGIA ENTRE A OBJETIVIDADE E SUBJETIVIDADE: ATUAÇÃO EM UMA ENFERMARIA DE SAÚDE MENTAL

subjetiva dos sujeitos, sem prejuízo da aplicação das técnicas estritamente fonoaudiológicas.

A boca representa personalidade, apetites, gostos, desejos e expectativas, e a língua permite a modulação vocal, adaptação das palavras às circunstâncias e a sensação dos diversos sabores dos alimentos ingeridos (Barreto, 2012); problemas relacionados a ela podem dizer das dificuldades em ingerir não só alimentos físicos quanto psicológicos, provenientes de experiências relacionais. Além disso, é pela boca, quando em sua adequada função, que é possível eliminar os alimentos insanos engolidos e que precisam ser expelidos e afastados (Barreto, 2012). Um sujeito não se reduz a uma lesão que Ihe provoca sofrimento, tampouco a um corpo com possíveis lesões ainda silenciosas, escondidas, à espera de um olhar que as descubra, muito menos se reduz a um conjunto de situações de risco (Mattos, 2001).

Propus a Rosa exercícios para aumentar a força, resistência e mobilidade das estruturas orofaciais e aumentar sensibilidade intra e extraoral, sem desconsiderar toda a trajetória e história de vida. Ao longo das semanas percebi que os exercícios chamados de "difíceis" estavam bastante semelhantes ao modelo que eu the dava e que os atendimentos se tornaram mais longos, pois Rosa cansava-se menos, segundo ela.

Rosa recebeu alta da internação e passou a ser acompanhada no ambulatório do próprio serviço hospitalar. Poucas semanas depois, juntamente com os demais profissionais que atendiam Rosa, referenciamos o caso para seu município.

\section{Conclusão}

Cabem aos casos clínicos de Margarida e Rosa as definições de Mattos (2001) acerca da integralidade da atenção. O autor define duas formas de 
A FONOAUDIOLOGIA ENTRE A OBJETIVIDADE E SUBJETIVIDADE: ATUAÇÃO EM UMA ENFERMARIA DE SAÚDE MENTAL

integralidade: integralidade focalizada e a integralidade ampliada. A integralidade da atenção precisa ser trabalhada em várias dimensões para que seja alcançada da forma mais completa possível. O fato de se reconhecerem as necessidades de ações específicas fonoaudiológicas além das demandas explícitas relacionadas ao sofrimento psíquico ilustraria o sentido da integralidade em ambos os casos apresentados.

Durante a experiência aqui retratada, tornou-se necessário não apenas desviar o olhar da patologia e do sintoma, muitas vezes intencionalmente focalizado por outros profissionais, mas desviar o olhar de um paradigma que estruturou e ainda estrutura a categoria profissional fonoaudiológica. Para tal, embora realizasse práticas tecnicistas, a perspectiva norteadora tornou-se outra e, por consequência, os processos terapêuticos também.

Há um desconhecimento da categoria profissional quanto às áreas de atuação dentro do campo da Saúde Mental, sendo identificada e legitimada apenas pelo seu saber técnico e especializado caracterizado por outras profissões e pelos próprios pares. Assim, defendemos neste trabalho que as ações especializadas do núcleo da Fonoaudiologia inseridas no campo da Saúde Mental não são intervenções determinantes do processo terapêutico, porém, assim como as diversas contribuições de outros núcleos profissionais, também são incorporadas como estratégias integradas ao processo de reabilitação psicossocial.

Não defendemos aqui que todo profissional fonoaudiólogo deva ser generalista, mas que mesmo o profissional especialista possa olhar para todas as áreas contempladas pela Fonoaudiologia a fim de buscar a integridade da clínica e ampliação do cuidado para cada sujeito assistido.

Reiteramos, a partir da discussão dos relatos clínicos e tantos outros casos não descritos neste trabalho, a importância de ações específicas fonoaudiológicas não apenas enquanto pretextos, mas como estratégias integrantes para promoção de saúde e cuidado para pessoas em sofrimento psíquico. A defesa em não considerar ações 
A FONOAUDIOLOGIA ENTRE A OBJETIVIDADE E SUBJETIVIDADE: ATUAÇÃO EM UMA ENFERMARIA DE SAÚDE MENTAL

fonoaudiológicas apenas como pretextos

é justificada por não negar o tecnicismo, mas sim integrá-lo a outros saberes que constituem o trabalho multiprofissional presente no campo da Saúde Mental.

A trajetória da Fonoaudiologia em busca do reconhecimento de sua identidade, além do entendimento das dificuldades existentes em integrar saberes específicos dentro da própria categoria profissional, justifica o desafio em integrar saberes clínicos fonoaudiológicos em defesa a um outro campo de conhecimento: a Saúde
Mental. O pressuposto aqui é de que não há uma fronteira rígida entre as dimensões objetiva e subjetiva, na medida em que se interpenetram e interagem sem, necessariamente, confundir-se.

Ao identificar a "clínica de empréstimos", propomos, com a elaboração deste texto, uma reflexão sobre a busca de uma clínica fonoaudiológica ampliada com os próprios embasamentos teóricos da profissão.

Devemos promover a ampliação do olhar e não a restrição.

\title{
Referências
}

\begin{abstract}
Almeida, B. P. B. (2014). Fonoaudiologia e Saúde Mental: atuação do fonoaudiólogo nos Centros de Atenção Psicossocial do Estado de São Paulo. Dissertação (Doutorado em Fonoaudiologia) - Pontifícia Universidade Católica de São Paulo. São Paulo.
\end{abstract}

Amarante, P. (2008). Saúde Mental e atenção psicossocial. Rio de Janeiro: Fiocruz.

Barreto, A. P. (2012). Quando a boca cala, os órgãos falam... desvendando as mensagens dos sintomas. Fortaleza: LCR. 
A FONOAUDIOLOGIA ENTRE A OBJETIVIDADE E SUBJETIVIDADE: ATUAÇÃO EM UMA ENFERMARIA DE SAÚDE MENTAL

Befi, L. D. M. (1997). A inserção da Fonoaudiologia na Atenção Primária à Saúde. In Befi, L. D. M. (Org.). Fonoaudiologia na atenção primária à saúde. São Paulo: Lovise, 1997: 15-35.

Bondía, J. L. (2002). Notas sobre a experiência e o saber de experiência. Revista Brasileira de Educação, (19), 20-28.

Brasil. Ministério da Saúde. Portaria n³ 3.588, de 21 de dezembro de 2017: altera as Portarias Consolidação $n^{\circ} 3$ e n 6, de 22 dezembro de 2017, para dispor sobre a RAPS, e dá outras providências. Diário Oficial da União 2017; 22 dez.

Brasil. Ministério da Saúde. Portaria SNAS/MS/INAMPS n²24, de 29 de janeiro de 1992. estabelece diretrizes e normas para o atendimento em saúde mental.

Brasil. Lei no 6965 de 9 de dezembro de 1981: dispõe sobre a regulamentação da profissão de Fonoaudiólogo, e determina outras providências. Brasília, DF, 1981.

Cunha, M. C. (2001). Fonoaudiologia e psicanálise: a fronteira como território. São Paulo: Plexus.

Dalgalarrondo, P.; Botega, N. J. \& Banzato, C. E. (2003). Pacientes que se beneficiam de internação psiquiátrica em hospital geral. Revista Saúde Pública, 37(5), 629-634.

Desviat, M. (2015). A reforma psiquiátrica. Tradução: Vera Ribeiro. 2. ed. Rio de Janeiro: Editora Fiocruz.

Dias, M. K.; Gonçalves, R. W \& Delgado, P. G. G. (2010). Leitos de atenção integral à saúde mental em hospital geral: configuração atual e novos desafios na política de saúde mental. In Vasconcelos, E. M. (Org.). (2010). Desafios políticos da reforma psiquiátrica brasileira. São Paulo: Hucitec. 
A FONOAUDIOLOGIA ENTRE A OBJETIVIDADE E SUBJETIVIDADE: ATUAÇÃO EM UMA ENFERMARIA DE SAÚDE MENTAL

Figueredo Neto, L. H. (1988). O início da prática fonoaudiológica na cidade de São Paulo: seus determinantes históricos e sociais. Dissertação (Mestrado em Distúrbio da Comunicação) - Pontifícia Universidade Católica de São Paulo. São Paulo.

Furtado, J. P. (2007). Equipes de referência: arranjo institucional para potencializar a colaboração entre disciplinas e profissões. Revista Interface, 11(22), 239-255.

Mattos, R. A. (2001). Os Sentidos da Integralidade: algumas reflexões acerca de valores que merecem ser defendidos. In Pinheiro, R. \& Mattos, R. A. (Orgs.). Os sentidos da integralidade na atenção e no cuidado à saúde. Rio de Janeiro: UERJ, IMS: ABRASCO, 39-64.

Mello, B. N. (2012). A noção psicanalítica de sintoma no tratamento fonoaudiológico. Revista Analytica, 1(1).

Miranda, G. M. D.; Mendes, A. C. G.; Silva, A. L. A. \& Rodrigues, M. (2015). Assistência fonoaudiológica no SUS: a ampliação do acesso e o desafio de superação das desigualdades. Revista CEFAC.

Moreira, M. D. \& Mota, H. B.(2009). Os caminhos da Fonoaudiologia no Sistema Único de Saúde - SUS. CEFAC, 11(3), 516-521.

Oliveira, F. (2002). Por uma terapêutica fonoaudiológica: os efeitos do discurso médico e do discurso pedagógico na constituição do discurso fonoaudiológico. Dissertação (Mestrado em Estudos da Linguagem) Pontifícia Universidade Católica de Porto Alegre. Porto Alegre.

Onocko Campos, R. T. \& Furtado, J. P. (2008). Narrativas: utilização na pesquisa qualitativa em saúde. Revista Saúde Pública, 42(6), 1090-1096.

Palladino, R. R. R. (2000). A objetividade e a subjetividade na Fonoaudiologia. Distúrbios da Comunicação, 12(1), 61-73. 
A FONOAUDIOLOGIA ENTRE A OBJETIVIDADE E SUBJETIVIDADE: ATUAÇÃO EM UMA ENFERMARIA DE SAÚDE MENTAL

Yasui, S. (2010). Rupturas e encontros: Desafios da reforma psiquiátrica brasileira. Rio de Janeiro: Editora Fiocruz.

Recebido em: 08/08/2020

Aprovado em: 15/12/2020 